Tema: Aciaria Oxigênio

\title{
SIMULAÇÕES NUMÉRICAS DA VAZÃO DE ÁGUA EM LANÇAS PARA BOF*
}

\author{
Breno Totti Maia ${ }^{1}$ \\ Bruno Orlando de Almeida Santos ${ }^{2}$ \\ Fabrício Silveira Garajau ${ }^{3}$ \\ Marcelo de Souza Lima Guerra
}

\section{Resumo}

Para uma boa operação das lanças de oxigênio para convertedores BOF é necessário existir uma boa condição de refrigeração, devido à agressividade existente no ambiente, onde ela fica exposta a condições de alta radiação, gases a alta temperatura e, algumas vezes, com o aço líquido. Para uma boa refrigeração, basicamente são necessários uma boa qualidade de água e condições adequadas de vazão e pressão. Mas somente esses fatores podem não garantir o desempenho adequado às condições de escoamento da água, devido à complexidade geométrica do bico da lança. Esse artigo tem como objetivo apresentar um estudo comparativo de escoamento da água, na parte crítica de uma lança que é o bico, destacando a importância da geometria interna do bico na troca térmica do equipamento. Serão apresentados os resultados comparativos, onde se observa que otimização do escoamento interno no bico da lança aumenta a vida útil do equipamento.

Palavras-chave: BOF; Bicos de lança; Vazão de água; Troca térmica; CFD.

\section{CFD SIMULATIONS FOR WATER FLOW IN LANCE TOP BOF}

\begin{abstract}
For a good operation of the oxygen lances for BOF converters is necessary to have a good cooling condition due environment aggressiveness where it is exposed to high light conditions, high temperature gases and sometimes the liquid steel. For a good cooling, are basically needed a good water quality and adequate conditions of flow and pressure. But these factors alone cannot ensure proper performance conditions for release of water due to geometric complexity at tip lance. This article aims to present a comparative study of water flow in the critical part, that is the nozzle, highlighting the importance of the internal tip geometry on heat exchange equipment. Comparative results are presented, which shows that optimization of internal flow at the nozzle boom increases equipment life.
\end{abstract}

Keywords: BOF; Lance tips; Water flow; Heat transfer; CFD.

1 Engenheiro Metalurgista, Doutor Pesquisador, Lumar Metals, sócio ABM, Belo Horizonte, MG, Brasil.

2 Engenheiro de Materiais, Pesquisador, Lumar Metals, sócio ABM, Santana do Paraíso, MG, Brasil.

3 Engenheiro Mecânico, Pesquisador, Lumar Metals, sócio ABM, Santana do Paraíso, MG, Brasil.

4 Engenheiro Mecânico, Pesquisador, Lumar Metals, sócio ABM, Santana do Paraíso, MG, Brasil.

* Contribuição técnica ao $45^{\circ}$ Seminário de Aciaria - Internacional, 25 a 28 de maio de 2014, Porto Alegre, RS, Brasil. 


\section{INTRODUÇÃO}

A lança de oxigênio é um equipamento constituído por tubulações de entrada de oxigênio, divisor de água e tubo externo contendo em uma das extremidades o bico de lança (feito em cobre fundido, forjado ou centrifugado com elevada pureza e garantindo uma extrema eficiência na condutividade térmica) com furos para saída e distribuição do oxigênio no convertedor (com geometria de saída precisamente calculada e usinada para garantir os valores de vazão e parâmetros de jato desejados). As tubulações montadas de forma concêntrica têm as seguintes funções: tubo central transporte de oxigênio, tubo intermediário a divisão entre a entrada e saída da água e tubo externo para conter a água de saída. A Figura 1 apresenta uma típica lança de sopro em convertedores BOF.

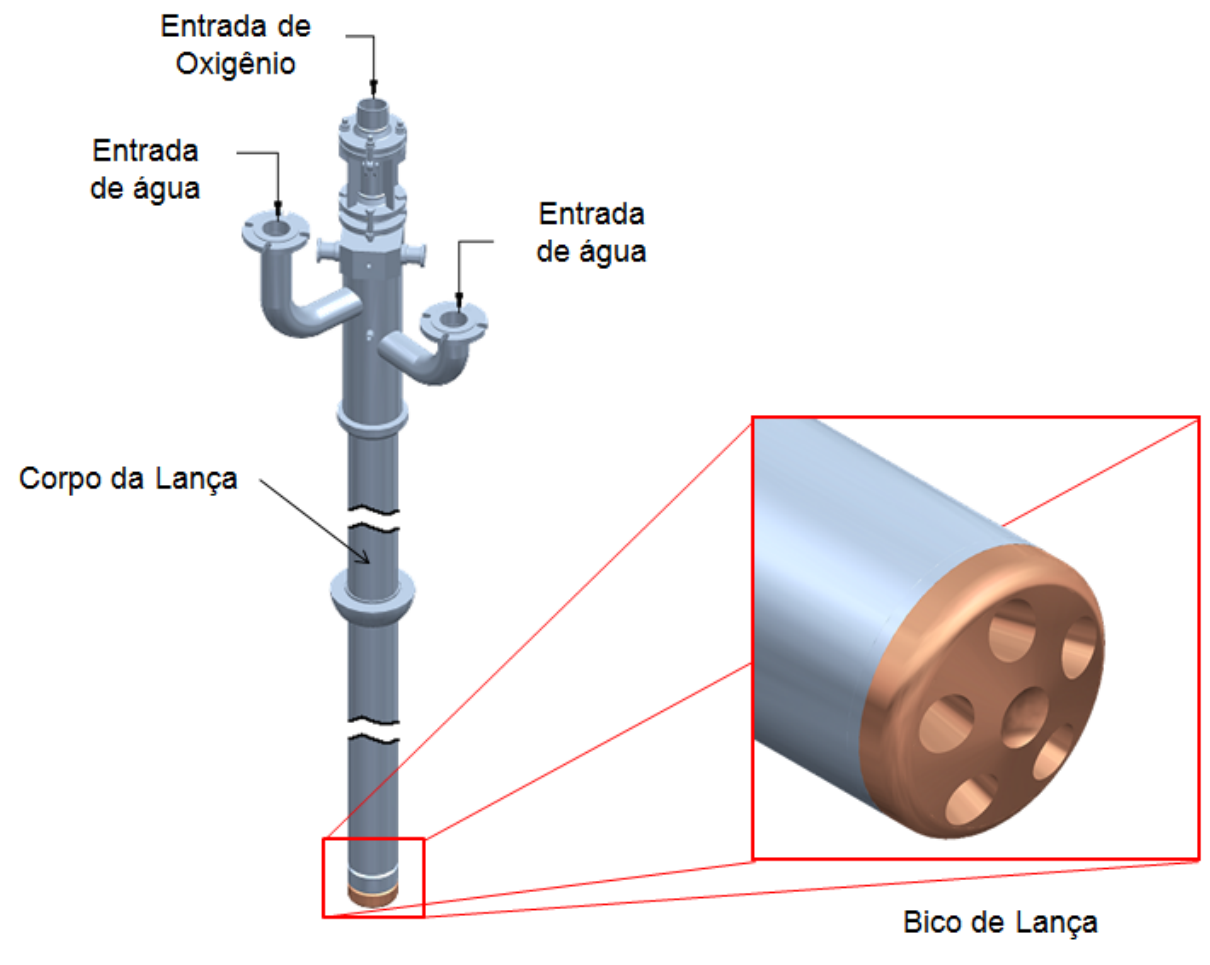

Fonte: Adaptado de Barker et al (1998).

Figura 1. Montagem típica de lança de sopro em convertedores a oxigênio [1].

As lanças devem ser projetadas para compensar expansões e contrações térmicas. O tubo externo da lança trabalha em elevadas temperaturas no interior do forno, e com o aumento da temperatura, ocorre a expansão de todas as estruturas no interior, sendo recomendada a utilização de anéis de vedação em todas as juntas, para acomodar as expansões e contrações durante o serviço. As lanças também devem ter um grau de liberdade que permitam absorver as movimentações que ocorrem durante o processo normal de operação.

A água de refrigeração é essencial nessas lanças, que devido a sua função de oxidar elementos do banho no interior do vaso durante o processo, fica exposta a elevadas temperaturas proveniente da radiação do banho metálico, contato com os gases gerados nas reações químicas e, em determinadas situações, contato com o aço líquido. Uma condição importante são os canais que conduzem a água para o centro do bico, em seguida refrigerando preferencialmente o centro do bico, região que sofre com elevadas temperaturas, para finalmente escoar pelas laterais do tubo

* Contribuição técnica ao $45^{\circ}$ Seminário de Aciaria - Internacional, 25 a 28 de maio de 2014, Porto Alegre, RS, Brasil. 
externo. O projeto deve buscar o máximo de velocidade de refrigeração da água no centro do bico.

A Figura 2 é um desenho esquemático em corte de um bico de lança típico, apresentado os bocais de passagem do oxigênio bem como os canais de entrada e saída de água de refrigeração.
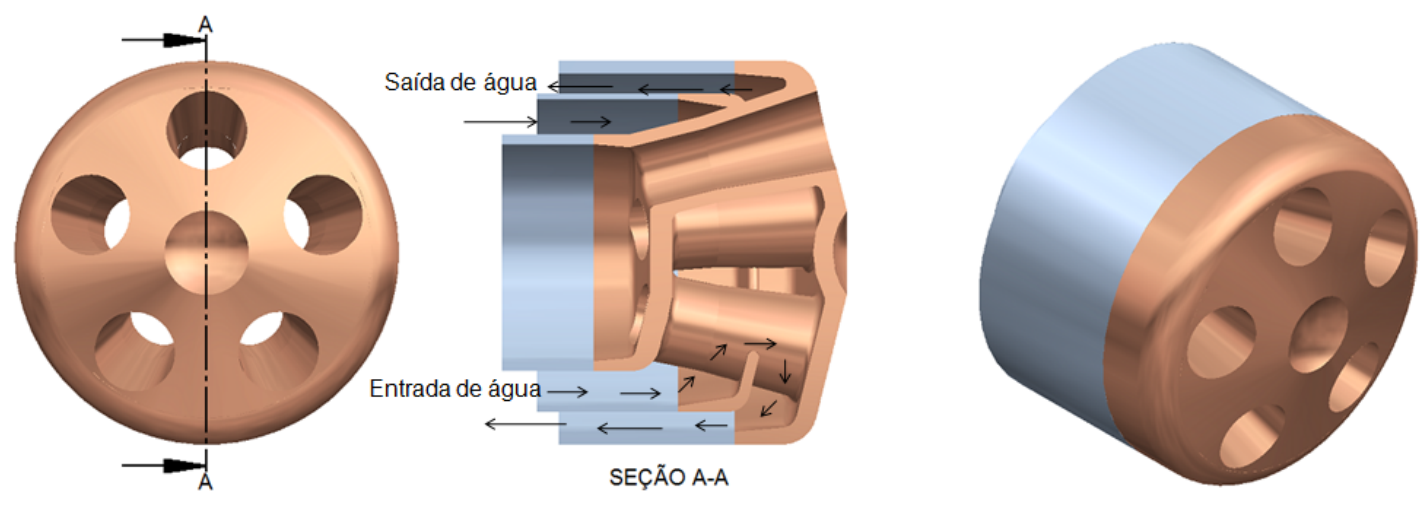

Figura 2. Figura esquemático de um típico bico de 05 furos.

Existem vários fatores que influenciam no desempenho e eficiência de uma lança, muitos deles diretamente ligados com as condições operacionais do convertedor. $\mathrm{O}$ silício do gusa em especial é um fator muito importante, pois seu efeito está diretamente ligado com a quantidade de escória formada e em como esta escória formada influência na penetração de jato, necessitando de controles operacionais para evitar a projeção de material particulado para fora do forno ou "slopping". A altura de operação da lança também é um parâmetro importante e deve ser incluída em conjunto com a geometria dos bocais. Se a lança está muito baixa no forno há uma exposição maior a temperaturas extremamente altas e a transferência de calor através da água pode não ser suficiente para manter as faces externas da lança a distância da poça de fusão e refino, podendo ser consumida prematuramente. Se a lança está muito alta, o jato de aço torna-se ineficiente devido a distância e será necessário uma maior quantidade de oxigênio para a necessária descarburação e temperatura do aço. A vazão de oxigênio é um parâmetro, em alguns casos, limitado pelo fornecimento ou emissão fugitivas. A velocidade de saída, em número de Mach, é um fator importante para determinação dos parâmetros de sopro (pressão e vazão de oxigênio) e dimensionamento dos lavais dos bicos de lança. Em geral, quanto maior o número de Mach, maior será a força do jato. Também é necessário considerar a quantidade de bocais, ou saídas e o ângulo das mesmas. Originalmente os convertedores BOF possuíam apenas um bocal direcionado para o banho sendo o causador de uma grande quantidade de projeções de material pela boca do vaso. Bicos com três bocais e ângulo suave foram desenvolvidos reduzindo as projeções e com ganhos consideráveis no rendimento da corrida. Atualmente os bocais variam entre 4 a 6 bocais. A vida dos bicos tem grande dependência das condições operacionais, mas um valor típico está em torno de 200 corridas, em alguns locais chegando a 400 corridas e em caso de extrema evolução do sistema de refrigeração chegando a 1000 corridas [2]. O sistema de refrigeração é um item critico, devendo ser mantida durante a operação conforme projeto. A temperatura da água, por segurança em bicos convencionais, nunca deve exceder $65^{\circ} \mathrm{C}$.

A qualidade de água não deve conter óxidos ou sujeiras, depósitos que podem acumular nas curvas existentes na face do bico resultando em uma baixa transferência de calor e consequentemente baixa vida. A altura operacional é

* Contribuição técnica ao 45 Seminário de Aciaria - Internacional, 25 a 28 de maio de 2014, Porto Alegre, RS, Brasil. 
decisiva na penetração do jato, entretanto, quando muito baixa pode comprometer a transferência de calor, mas por outro lado, baixas vazões de oxigênio favorece a erosão nos bocais do bico de lança. Com o acumulo excessivo de cascões ao longo do corpo da lança, torna-se necessária uma limpeza mecânica ou por oxicorte que em ambas as práticas pode causar danos e perda de eficiência.

\section{MATERIAIS E MÉTODOS}

Para o estudo do comportamento do escoamento do fluido de refrigeração nos bicos de lança, foi adotada uma linha de estudo utilizando simulação computacional através do software comercial ANSYS-CFX, que trabalha as equações de conservação para promover os perfis e coeficientes internos para o correto dimensionamento do equipamento, que será dividido abaixo em Modelagem Matemática e Numérica.

Os resultados práticos serão comparados aos resultados computacionais, sendo avaliado o ganho de vida útil do bico de lança com as alterações feitas no projeto baseadas nos resultados das simulações computacionais.

\subsection{Modelagem Matemática}

Para este caso, o fluido de refrigeração é tratado como um contínuo sempre em termos das propriedades macroscópicas, tais como velocidade, pressão, densidade e temperatura, e os seus derivados, no espaço e tempo [3]. Propriedades tais como a estrutura microscópica e movimentos moleculares são ignorados. Variáveis das equações de conservação que governam o movimento do fluido são resolvidas para a fase líquida, tal como resumido na Tabela 1.

Tabela 1. Equações de conservação para a fase líquida

$$
\begin{array}{cl}
\text { Massa } & \frac{\partial \rho}{\partial t}+\nabla \cdot(\rho \vec{U})=S_{m} \\
\text { Momento } & \frac{\partial}{\partial t}(\rho U)+\nabla \cdot(\rho \vec{U} \vec{U})=-\nabla p+\nabla \cdot(\bar{\tau})+\rho \vec{g}+\vec{F} \\
\text { Energia } & \frac{\partial\left(\rho h_{\text {tot }}\right)}{\partial t}-\frac{\partial p}{\partial t}+\nabla \cdot\left(\rho U h_{\text {tot }}\right)-\nabla \cdot(k \nabla T)+\nabla \cdot(U \cdot \tau)+U \cdot S_{M}+S_{E} \\
\text { Energia } & \frac{\partial(\rho k)}{\partial t}+\frac{\partial}{\partial x_{j}}\left(\rho U_{j} k\right)=\frac{\partial}{\partial x_{j}}\left[\left(\mu+\frac{\mu_{t}}{\sigma_{k}}\right) \frac{\partial k}{\partial x_{j}}\right]+P_{k}-\rho \varepsilon+P_{k b} \\
\text { Cinética } \\
\text { Turbulenta } \\
\quad \text { Taxa } & \frac{\partial(\rho \varepsilon)}{\partial t}+\frac{\partial}{\partial x_{j}}\left(\rho U_{j} \varepsilon\right)=\frac{\partial}{\partial x_{j}}\left[\left(\mu+\frac{\mu_{t}}{\sigma_{\varepsilon}}\right) \frac{\partial \varepsilon}{\partial x_{j}}\right]+\frac{\varepsilon}{k}\left(C_{\varepsilon 1} P_{k}-C_{\varepsilon 2} \rho \varepsilon+C_{\varepsilon 1} P_{\varepsilon b}\right) \\
\text { Dissipação } \\
\text { Tubulenta }
\end{array}
$$

\subsection{Modelagem Numérica}

Técnicas de fluidodinâmica computacional (CFD - Computational fluid dynamics) já vêm sendo implementadas desde a decada de 1960 [4]. Todo o desenvolvimento das técnicas computacionais aplicadas à solução de escoamentos foi inicialmente alavancado pelo campo da engenharia aeronáutica. Devido à limitação dos recursos computacionais de épocas atrás, a solução de escoamentos aerodinâmicos era feita através da simplificação do conjunto de equações governantes [4]. Como os efeitos

* Contribuição técnica ao $45^{\circ}$ Seminário de Aciaria - Internacional, 25 a 28 de maio de 2014, 


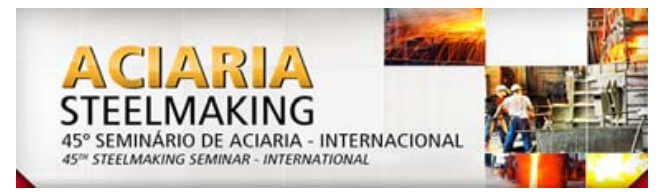

viscosos são limitados a uma região muito delgada e próxima às paredes (camada limite), assumiu-se, para efeitos de cálculo, que os escoamentos eram irrotacionais e não-viscosos. Atualmente as simulações computacionais estão sendo amplamente aplicadas para resolução de problemas de dinâmica dos fluidos graças a grande evolução dos recursos computacionais que ocorreu nesta década [5].

Para estudar o comportamento do fluido refrigerante nos bicos de lança, considerando as condições entrada, saída, bem como o aporte térmico proveniente das reações do forno, foi utilizado uma geometria que abrange as dimensões de um bico de lança de 5 furos, conforme mostrado na Figura 3.
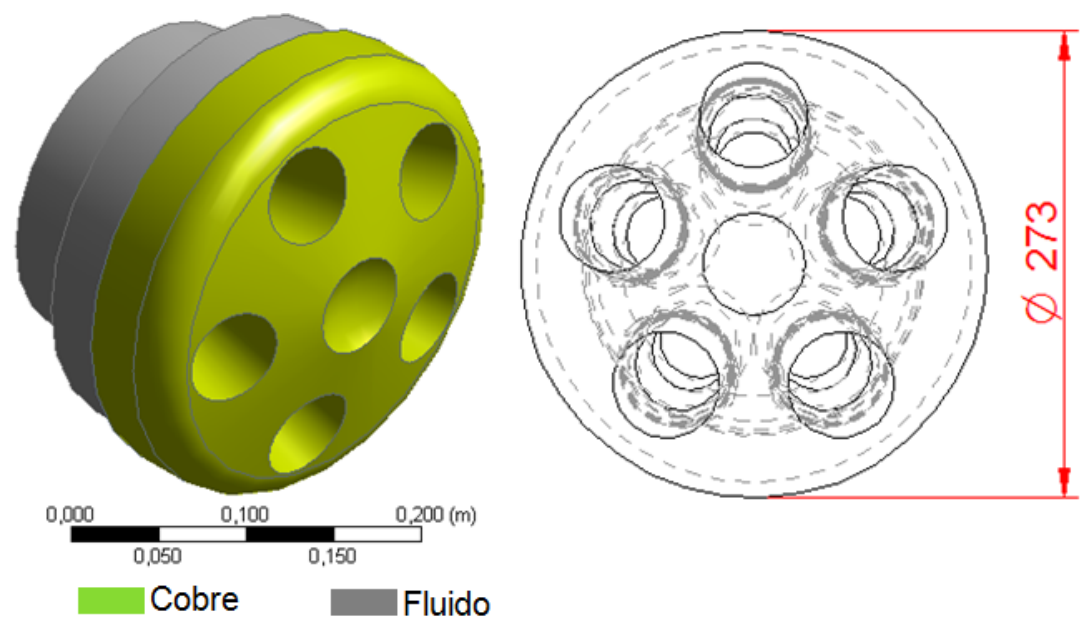

Figura 3. Geometria 3D do bico de lança.

A geometria apresentada na Figura 3Erro! Fonte de referência não encontrada. foi empregada em todos os domínios testados. A variação ocorreu no projeto do bico de lança, onde os perfis de circulação internos foram variados. As entradas e saídas foram mantidas constantes e estão mostradas na Tabela 2.

Tabela 2. Condições de Contorno para análise

\begin{tabular}{cc}
\hline Descrição & Valores \\
\hline Vazão de água & $170 \mathrm{~m}^{3} / \mathrm{h}$ \\
\hline Temperatura de Entrada da água & $40^{\circ} \mathrm{C}$ \\
\hline Fluxo de Calor (Frente Bico) & $2,4 \mathrm{MW} / \mathrm{m}^{2}$ \\
\hline
\end{tabular}

O processo de geração de malha exige uma análise prévia da geometria. O cuidado com a geometria favorece a geração de malhas mais regulares, benéfico tanto para convergência dos resultados, como para a redução do número de elementos que compõem o domínio. Para o presente estudo, pode-se separar a malha em duas regiões. A primeira é a região do fluido, que deve contemplar camadas próximas a parede para captar os efeitos da viscosidade e perda de carga para aproximar os resultados dos valores práticos de operação. A segunda região é o corpo sólido, que também deve contemplar camadas de elementos para a correta transferência dos campos de concentração e temperatura ao longo da espessura do material. Ambos devem ser conectados através de interface para garantir a interação entre os domínios fluido e sólido, sem perda de informação. As principais condições de contorno e estrutura de malha estão apresentadas na Figura 4.

* Contribuição técnica ao 450 Seminário de Aciaria - Internacional, 25 a 28 de maio de 2014, Porto Alegre, RS, Brasil. 

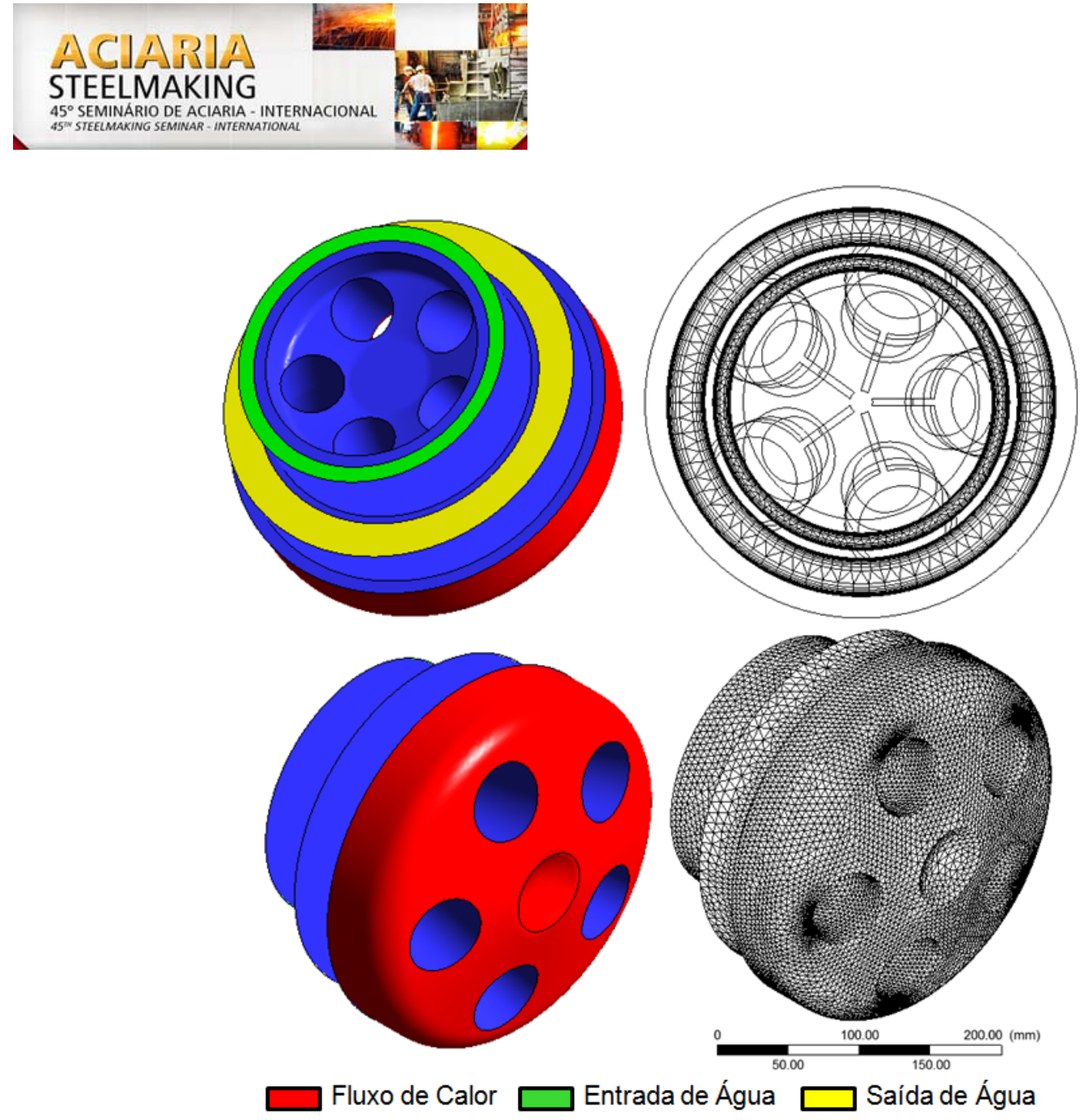

Figura 4. Condições de contorno e Malha da geometria.

\section{RESULTADOS E DISCUSSÃO}

Os resultados das simulações computacionais foram separados em três condições de análise: Perfis de velocidade do fluido de refrigeração, temperatura da face do bico, da água de saída e variação de pressão do fluido na geometria analisada. Deve-se destacar que estas três condições devem ser monitoradas para garantir que os valores de processo prático estejam bem aplicados para o modelo computacional, buscando representar de forma mais aproximada o comportamento do equipamento em operação.

Também será apresentado um comparativo da variação de projetos com redução de temperatura e aumento de eficiência.

\subsection{Perfil de Velocidade}

A posição em que o bico de lança trabalha, expõe sua face a condições de alta temperatura e também de possíveis esforços mecânicos de abrasão/erosão, promovendo desgastes e falhas no equipamento. Trabalhar os perfis de velocidade do fluido de refrigeração contribui em muito na redução dos danos ao equipamento, visto que a velocidade de escoamento e como consequência sua turbulência, tem impacto direto nos coeficientes de transferência de calor do canal de refrigeração.

Para este bico de lança, os perfis de velocidade podem ser observados através da Figura 5. É possível notar que há uma baixa velocidade no centro do bico, exatamente na região onde se tem maior exposição do equipamento às agressivas condições durante o processo de sopro da corrida.

* Contribuição técnica ao $45^{\circ}$ Seminário de Aciaria - Internacional, 25 a 28 de maio de 2014, 

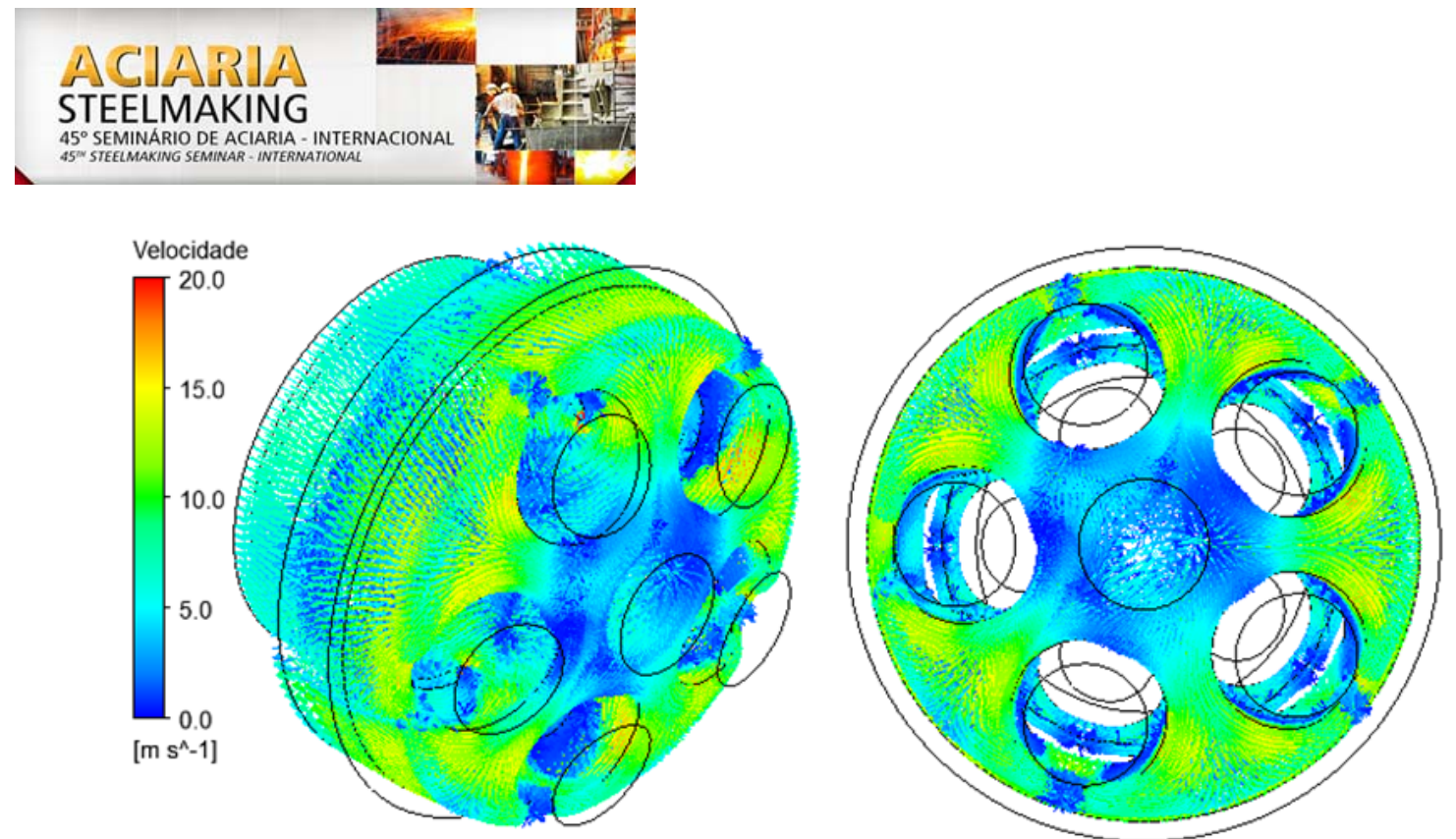

Figura 5. Perfil de velocidade do fluido de refrigeração.

A baixa velocidade do fluido gera também baixos valores de coeficiente de convecção que reduzem a eficiência de troca térmica do equipamento naquela região.

\subsection{Perfil de Temperatura}

Apesar do fluxo de calor constante em toda face do bico, o perfil de temperatura está diretamente relacionado com o perfil de velocidade do fluido de refrigeração. Dessa forma, é possível observar através da Figura 6a, uma elevação na temperatura do bico na região central do bico. Esta elevação na temperatura está relacionado à baixos valores dos coeficientes de transferência de calor por convecção no interior do bico. Também é possível observar através da Figura $6 \mathrm{~b}$ que a região de maior desgaste e falha do equipamento ocorre exatamente na região de maior temperatura do material.
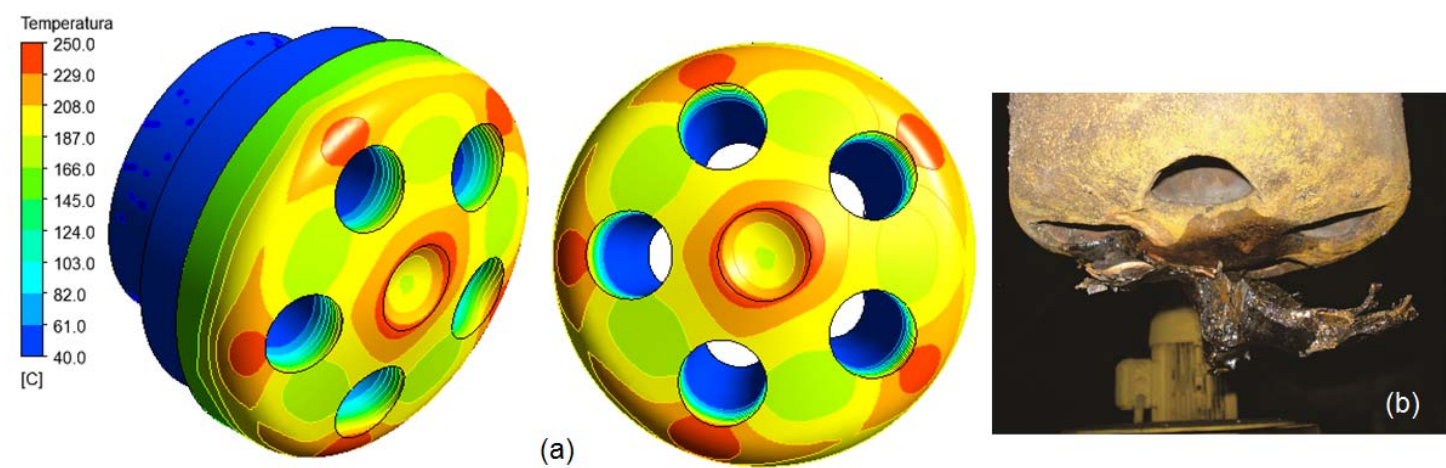

Figura 6. Perfil de Temperatura do Bico de Lança (a) coincidindo com região de desgaste e furo do bico (b).

Nota-se também que na região atrás dos lavais (bocais) de oxigênio, também há um aumento de temperatura, que pode ser explicado pela dificuldade do fluido contornar o laval e atingir aquela região. Porém, na prática, esta não é uma região de grande desgaste, devido estar protegida pelo jato de oxigênio, que normalmente possui uma angulação de saída, favorecendo esta proteção.

* Contribuição técnica ao 45 Seminário de Aciaria - Internacional, 25 a 28 de maio de 2014, 


\subsection{Variação de Pressão}

A variação de pressão no interior do bico de lança é um dos fatores mais importantes no dimensionamento desse equipamento. Isto porque se a variação de pressão (perda de carga) for muito grande, provavelmente este não atingirá as vazões e velocidades recomendadas para o projeto, podendo reduzir sua vida útil consideravelmente. A Figura 7 mostra as regiões de maior perda de carga no bico de lança estudado.
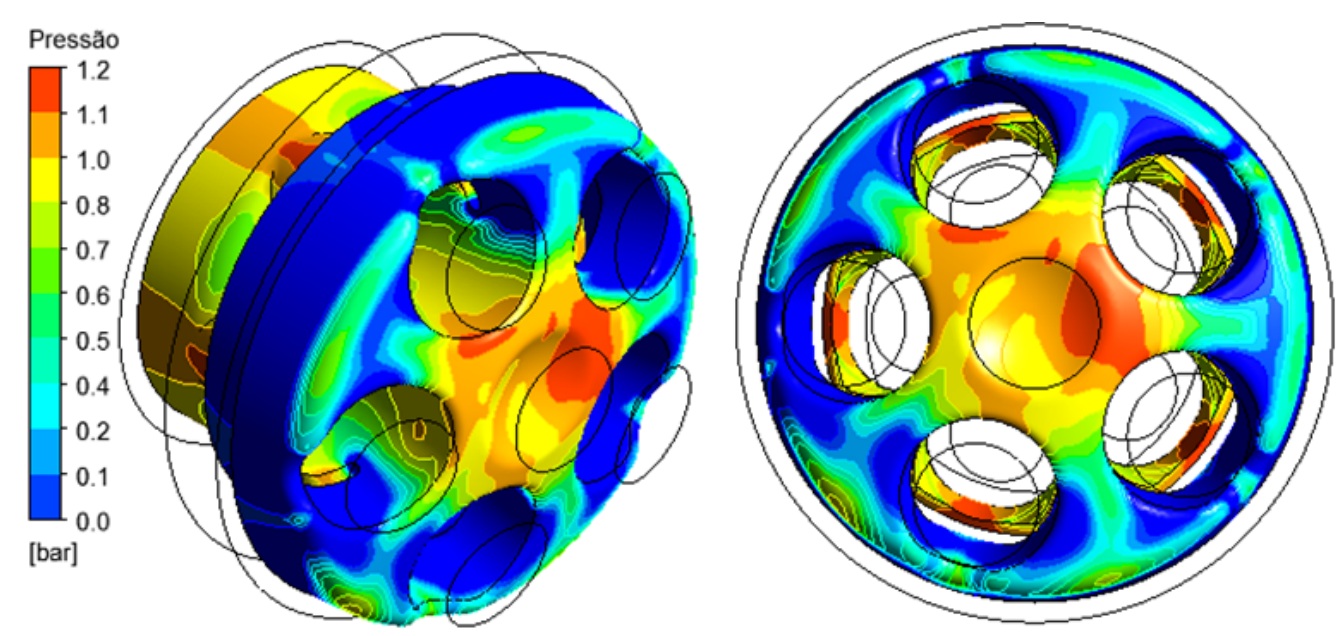

Figura 7. Variação de pressão ao longo do bico de lança.

\subsection{Comparativo de Projetos}

É possível, através de avaliação das condições de contorno e principalmente de alterações de projeto, atingir ganhos consideráveis em eficiência de refrigeração, elevando a vida útil do equipamento e trazendo maior controle operacional para a planta siderúrgica. A Figura 8 mostra com clareza o efeito da modificação de projeto objetivando maior eficiência na refrigeração do bico. É possível notar que a região central do bico de lança que apresentava elevação de temperatura foi reduzida simplesmente alterando as condições de escoamento interno.
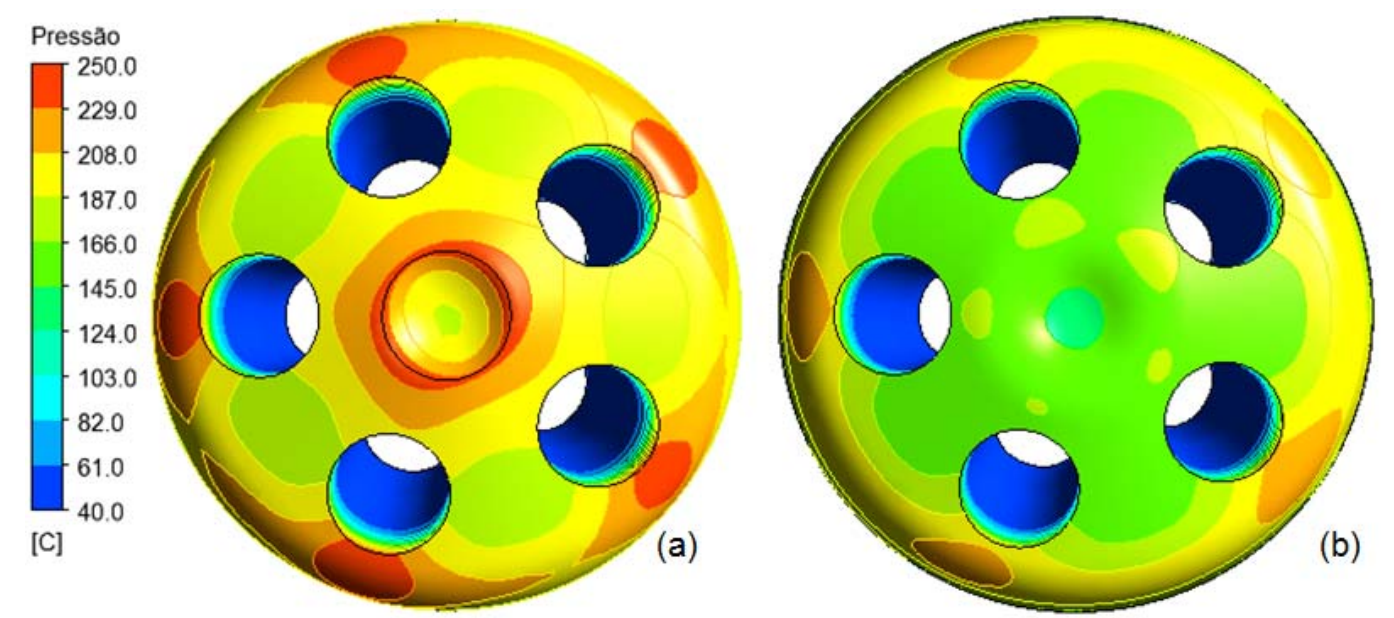

Figura 8. Perfil de temperatura do bico original (a) e do bico com modificação de projeto (b).

* Contribuição técnica ao $45^{\circ}$ Seminário de Aciaria - Internacional, 25 a 28 de maio de 2014, Porto Alegre, RS, Brasil. 


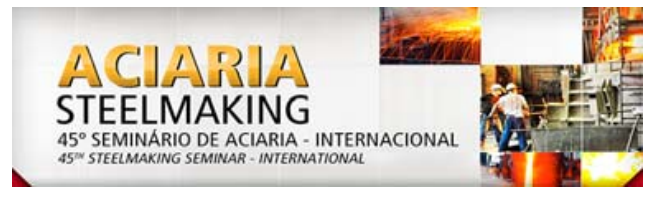

Esta redução na temperatura do bico de lança reflete também no aumento das propriedades mecânicas do material. Trabalhando em temperaturas reduzidas, 0 material mantém as características mecânicas, reduzindo sua tendência a danos por abrasão de fagulhas e particulados e aumenta a vida, retardando os efeitos de fadiga do material.

O perfil de velocidade do fluido de refrigeração interno, capaz de gerar os altos coeficientes de transferência de calor pode ser vistos na Figura 9. Quando comparado o projeto modificado ao bico original, percebe-se uma grande evolução nestes valores.
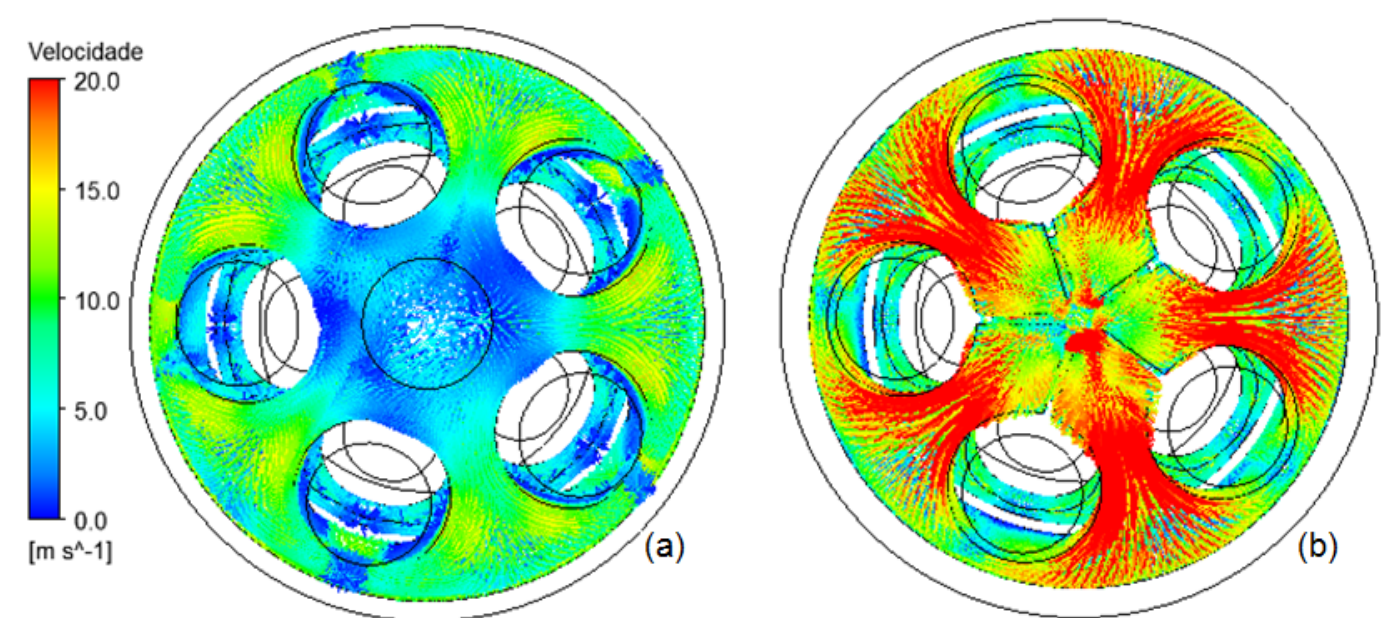

Figura 9. Perfis de Velocidade do fluido de refrigeração bico original (a) e projeto modificado (b).

Comparando os resultados práticos, que podem ser observados na Figura 10, pode-se verificar que os conceitos aplicados na refrigeração do bico obtiveram ganhos expressivos no aumento de vida útil do equipamento.
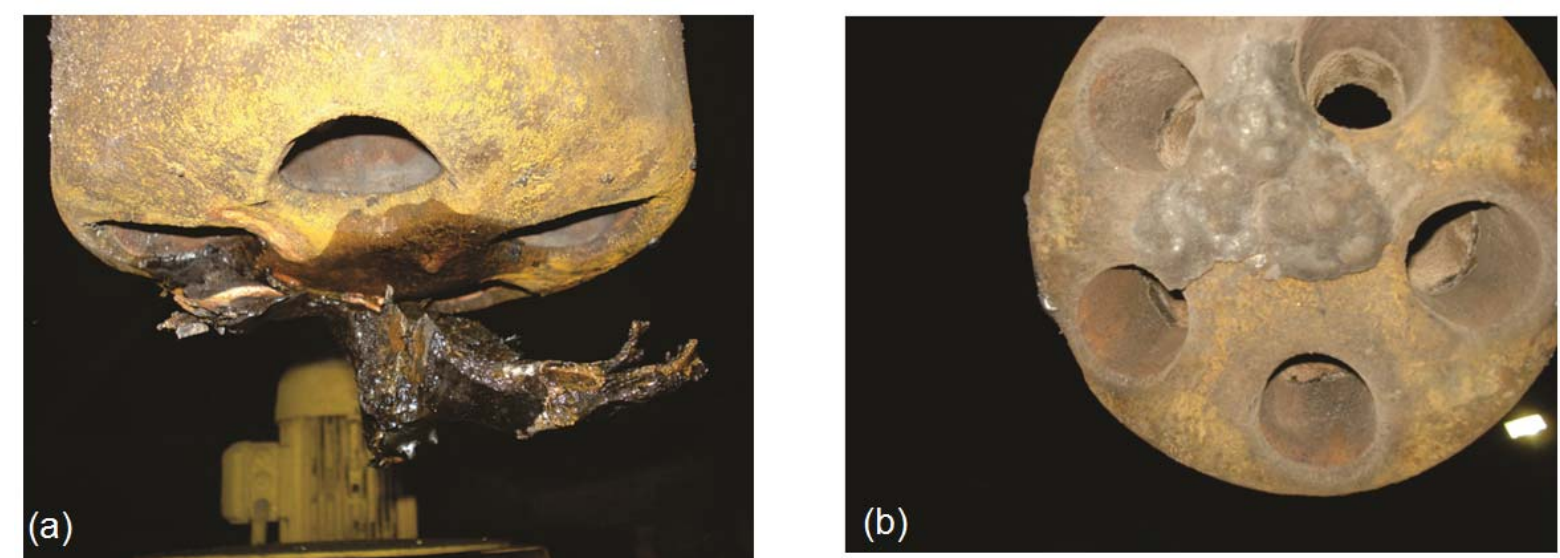

Figura 10. Comparação de vida útil (a) bico atual com 166 corridas e (b) projeto modificado com 990 corridas e retirado por medidas preventivas.

\section{CONCLUSÃO}

Foi possível concluir através dos resultados que a alteração de projeto objetivando redução nos perfis de temperatura tem grande influência no desempenho do equipamento. Os bicos de lança, que são utilizados em convertedores e que normalmente estão expostos a altas temperaturas, também sofrem com eventuais impactos por fagulhamento, projeção e abrasão/erosão de particulados. Trabalhar

* Contribuição técnica ao 450 Seminário de Aciaria - Internacional, 25 a 28 de maio de 2014, Porto Alegre, RS, Brasil. 
com a ponta do bico com baixa temperatura ajuda a manter as propriedades mecânicas elevadas, garantindo a resistência necessária para uma maior longevidade do equipamento.

\section{Agradecimentos}

Os autores agradecem a Lumar Metals pelo incentivo à pesquisa.

\section{REFERÊNCIAS}

1 Barker KJ, Paules JR, Rymarchyk N, Jancosko RM. Oxygen Steelmaking Furnace. Mechanical Description and Maintenance Considerations. In: Steelmaking and Refining Volume; 1998. Pittsburg: The AISE Steel Foundation, Inc. 1998. cap.8.

2 Maia BT. Modelamento Físico e Matemático do Escoamento de Fluidos nos processos BOF e EOF [tese doutorado Engenharia Metalúrgica]. Belo Horizonte: Escola de Engenharia da UFMG, 2013. p.238.

3 Ansys CFX [programa de computador]. V14.1. Canonsburg: Ansys; 2012.

4 Odenthal HJ, Emling WH, Kempken J, Schluter J. Advantageous Numerical Simulation of the Converter Blowing Process. In: AIST. AISTech Conference Proceedings; 2007. Pittsburg: AIST; 2007.

5 Vasconcelos DB. Introdução à mecânica dos Fluidos Computacional. Rio de Janeiro: ESSS; 2011.

* Contribuição técnica ao 45 Seminário de Aciaria - Internacional, 25 a 28 de maio de 2014, Porto Alegre, RS, Brasil. 